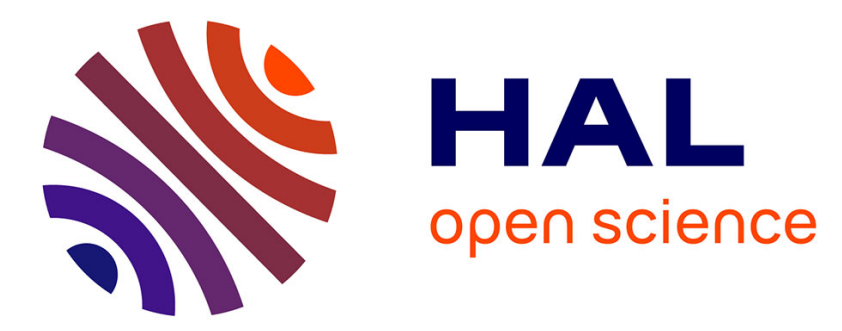

\title{
Effect of Axial Compressive Damage on Gas Permeability of Ordinary and High Performance Concrete
}

\author{
Vincent Picandet, Abdelhafid Khelidj, Guy Bastian
}

\section{- To cite this version:}

Vincent Picandet, Abdelhafid Khelidj, Guy Bastian. Effect of Axial Compressive Damage on Gas Permeability of Ordinary and High Performance Concrete. Cement and Concrete Research, 2001, 31 (11), pp.1525-1532. 10.1016/S0008-8846(01)00546-4 . hal-01006773

HAL Id: hal-01006773

https://hal.science/hal-01006773

Submitted on 22 Nov 2018

HAL is a multi-disciplinary open access archive for the deposit and dissemination of scientific research documents, whether they are published or not. The documents may come from teaching and research institutions in France or abroad, or from public or private research centers.
L'archive ouverte pluridisciplinaire HAL, est destinée au dépôt et à la diffusion de documents scientifiques de niveau recherche, publiés ou non, émanant des établissements d'enseignement et de recherche français ou étrangers, des laboratoires publics ou privés. 


\title{
Effect of axial compressive damage on gas permeability of ordinary and high-performance concrete
}

\author{
Vincent Picandet*, Abdelhafid Khelidj, Guy Bastian \\ Laboratoire de Ge'nie Civil de Nantes-Saint-Nazaire, I.U.T. Département Génie Civil, 58 rue Michel Ange, BP 420, 44606 Saint-Nazaire Cedex, France
}

Gas permeability is commonly used to evaluate durability characteristics of concrete. However, these values are often achieved using never stressed or damaged specimens. The objective of this study is to examine experimentally the effect of axial compressive loading on the permeability of three different types of concrete: ordinary concrete (OC), high-performance concrete (HPC), and high-performance steel fiber-reinforced concrete (HPFC). Monotonic and cyclic loads are applied on $220 \times 110-\mathrm{mm}$ diameter specimens. Stress levels vary between $60 \%$ and $90 \%$ of the ultimate strength. At the end of the loading phase, a disc is extracted from the middle part of the cylinders and is dried in a ventilated oven. Four different gas permeability tests are conducted during the drying procedure. The results show that, for each drying stage, the gas permeability of the discs increases with the load-induced strain. A correlation is worked out between the increase in permeability and the applied-strain/yield-strain ratio. Finally, a relationship between mechanical damage indicators and the increase in permeability is also discussed.

Keywords: Permeability; Durability; Microcracking; High-performance concrete; Strain effect

\section{Introduction}

The permeability of concrete is regarded as a basic indicator of its durability. It is, however, commonly measured on non-mechanically-damaged specimens. The inservice damages are then ignored. Knowledge of the transfer properties of both sound and cracked concrete is essential to predict its durability since the deteriorating mechanisms, such as leaching, corrosion, and freezing, depend on the flow of liquid or gaseous aggressive agents through the porous or cracked medium.

The present study was conducted to characterize the effect of external load-induced cracking on the permeability of concrete after unloading. A load applied up to the ultimate strength (i.e., in postpeak phase) is assumed to involve extensive damage in the specimen generating macroscopic cracking and, therefore, a sharp increase in permeability [1-3]. Within the prepeak phase, (e.g., when

\footnotetext{
* Corresponding author. Tel.: +33-2-40-17-86-17; fax: +33-2-40-1781-60.

E-mail address: vincent.picandet@iutsn.univ-nantes.fr (V. Picandet).
}

the stress-strength ratio does not exceed $90 \%$ ), cracking is more diffuse and results in microcracks. Some studies show a slight increase in the water permeability of specimens after unloading $[4,5]$. On the contrary, a previous study showed a sharp increase in permeability above $40 \%$ of the ultimate strength [6]. However, assessing mechanical microcracking with a water permeability test, especially in high-performance concrete (HPC), is difficult due to water-cement matrix interactions [5]. Cracking may occur as a result of the exposure of previously unhydrated components and also, dissolution and precipitation of hydrates, resulting in the autogeneous healing of cracks [7].

Concerning gas permeability measurements, most studies apply testing-under-load procedures to amplify permeability variations. Results are thus more representative of the inservice material. However, due to the difficulty of the implementation, these experiments are limited to the study of mortar [8] or of radial gas flows in the axial loaded cylinder of ordinary concrete [9]. The present experimental study was conducted to achieve further information on the influence of load-induced cracking on the permeability of ordinary concrete and of HPC. After unloading the specimens are prepared for testing in a standard permeameter cell 
where their moisture conditioning is carefully controlled. The gas permeability measurement of concrete has, then, the advantage of being precise and quick. The influence of both maximum load-induced strain and drying on gas permeability of three concrete mixes is also examined. Finally, the determination of a damage-permeability relationship is attempted.

\section{Experimental program}

\subsection{Materials, mix proportion, and specimen curing}

Three concrete mixes are made; one of ordinary concrete (OC) with a water/cement ratio of 0.5 , and two of highperformance concrete (HPC), with similar composition save that one is reinforced with steel fiber (HPFC) with a water/ cement ratio of 0.3 (Table 1 ). The last mix contains a $1 \%$ volume fraction of end-hooked steel fibers $(30 \mathrm{~mm}$ length and $0.38 \mathrm{~mm}$ diameter).

Twenty $110 \times 220-\mathrm{mm}$ cylindrical samples are prepared from a single batch for each mix. The concrete mixtures are cast in steel molds and compacted using a mechanical vibrator. The cylindrical specimens are stored in a room maintained at $20^{\circ} \mathrm{C}$ with a $95 \%$ relative humidity $(\mathrm{RH})$ for $24 \mathrm{~h}$ after casting, and are cured in water at $20^{\circ} \mathrm{C}$ for 4 weeks. They are then put in a nonventilated drying oven and heated at $60^{\circ} \mathrm{C}$ for 2 days. Finally, they are stored in an airconditioned room $\left(20 \pm 1{ }^{\circ} \mathrm{C}\right.$ and RH $\left.50 \pm 5 \%\right)$ for 4 months until testing. Their mechanical characteristics and material properties at 28 days are measured (Table 2).

\subsection{Mechanical damaging}

Mechanical damage is achieved applying uniaxially compressive loading on the $220 \times 110$-mm diameter concrete cylinders using a programmable hydraulic press under load control. The stress level is preset and applied under cyclic loading. These cycles include a minimum stress stage of 3.5 MPa and a maximum stress stage of a preset value for each cylinder test, varying from $60 \%$ to $90 \%$ of the ultimate strength. The time period observed at each stage to allow for

Table 1

Details of test series and mix proportion

\begin{tabular}{llll}
\hline Mix ingredients $\left(\mathrm{kg} / \mathrm{m}^{3}\right)$ & OC & HPC & HPFC \\
\hline Coarse aggregate, $12.5-20 \mathrm{~mm}$ & 777 & - & - \\
Medium aggregate, $4-12.5 \mathrm{~mm}$ & 415 & 1011 & 966 \\
Sand (Boulonnais), 0-5 mm & 372 & - & - \\
Sand (Loire), 0-4 mm & 372 & 722 & 690 \\
Cement CPA-CEM I 52.5 & 353 & 400 & 400 \\
Silica fume & - & 40 & 40 \\
Steel fiber & - & - & 79 \\
Plasticizer & - & 6 & 10 \\
Filler & - & 72.2 & 69 \\
Total water & 172 & 140 & 140 \\
w/c ratio & 0.49 & 0.29 & 0.29 \\
\hline
\end{tabular}

Table 2

Material properties

\begin{tabular}{lccc}
\hline & OC & HPC & HPFC \\
\hline Modulus of elasticity $(\mathrm{GPa})$ & 42 & 45 & 46 \\
Compressive strength $(\mathrm{MPa})$ & 65 & 110 & 130 \\
Yield compressive strain $(\mu \mathrm{m} / \mathrm{m})$ & 2100 & 2950 & 3420 \\
Dry apparent density $\left(\mathrm{g} / \mathrm{cm}^{3}\right)$ & 2.34 & 2.35 & 2.41 \\
Open porosity measured by & 12.1 & 9.6 & 10.4 \\
$\quad$ water saturation (\%) & & &
\end{tabular}

the crack propagation is $2 \mathrm{~min}$. The stress rate of loading and unloading is $0.45 \mathrm{MPa} / \mathrm{s}$. The load is successively applied on six concrete cylinders of each concrete type as shown in Table 3 (i.e., a total of 18 samples are loaded).

During loading, because of friction, some radial compressive stresses develop close to the end faces of a compressed specimen and keep the vertical crack density rather low while the central portion of specimen undergoes extensive cracking. The failure mode of the concrete can be then considered as a combination of local tensile mechanisms $[10,11]$. In prepeak phase, diffuse damage is obtained and microcracking is assumed to be distributed within the volume of the midheight section.

The longitudinal strain at the midsection of the test cylinders is measured using an extensometer cell equipped with three linear variable displacement transducers (LVDT), with a range agreeing within $0.5 \mathrm{~mm}$ and an accuracy of $1 \mu \mathrm{m}$, see Fig. 1. The transducers are laid every $120^{\circ}$ intervals to account for any asymmetric longitudinal strain. The displacements are recorded during the whole loading phase and $30 \mathrm{~min}$ after unloading.

\subsection{Dynamic modulus measurement}

The dynamic modulus measurements of the concrete cylinders are carried out immediately before and after loading. The 'Grindosonic' apparatus is used. This nondestructive test is based on the measurement of a stationary acoustic wave frequency inside the concrete cylinders in two vibration modes (torsional and flexural) [12]. The decrease recorded in the dynamic modulus is due to the appearance of microcracks inside the material during the loading phase.

\subsection{Preparation of the samples and drying procedure}

Concrete cylinders are cut using a diamond blade saw to obtain $50 \mathrm{~mm}$-thick discs. One disc is extracted from each central portion of the cylinder after loading, as shown in Fig. 1. The discs are then ground true. Their thickness is

Table 3

Loading program

\begin{tabular}{lrrrl}
\hline Number of specimens & 1 & 1 & 1 & 3 \\
Stress - strength ratio (\%) & 60 & 70 & 80 & 90 \\
Number of cycles & 10 & 10 & 10 & 1,3 , and 10 \\
\hline
\end{tabular}




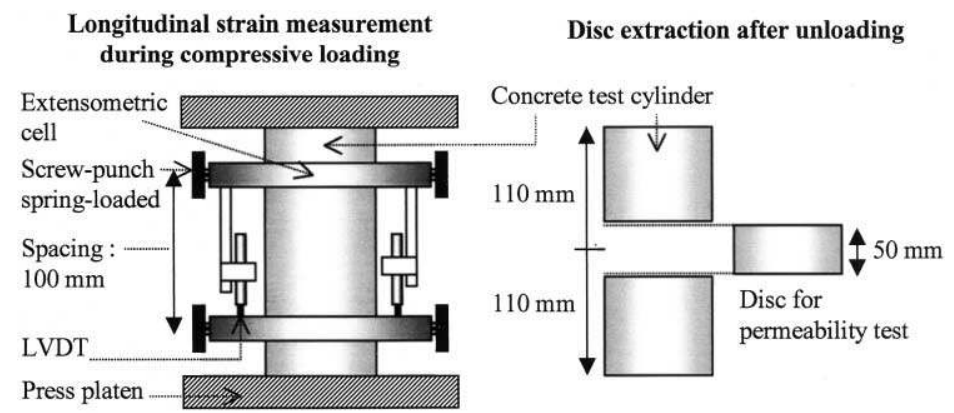

Fig. 1. Preparation of the samples: Strain measurement of concrete cylinders during loading and extraction of the discs.

measured with an accuracy of $0.1 \mathrm{~mm}$. Their curved surface is sealed with two epoxy resin coats to ensure a onedimensional gas flow inside the discs.

Drying the discs before proceeding to any gas permeability test is necessary. Both the drying modes and the water saturation degree have a direct influence on the gas permeability of concrete $[13,14]$. The discs are first ovendried at $60^{\circ} \mathrm{C}$ for 1 month. Then, they are cooled for $48 \mathrm{~h}$ in a desiccator at $20^{\circ} \mathrm{C}$ before being tested. Their mass is then measured with an accuracy of $0.02 \mathrm{~g}$ to determine their moisture content. The procedure of the first drying stage has been selected because it is thought to not damage the microstructure of concrete and allows for enough gas percolation. However, to maintain a homogenization of the degree of saturation between the different types of samples, the drying procedure must be extended [15]. Drying is then carried on as shown in Table 4: three additional drying stages including additional months in a ventilated oven at $80^{\circ} \mathrm{C}$ and $105^{\circ} \mathrm{C}$.

It must be noted that gas permeability is here used to gage the internal damage caused by externally applied loads only. Superficial damages due to drying at $105^{\circ} \mathrm{C}$ are assumed identical for all the discs of a same series.

\subsection{Gas permeability test procedure}

Intrinsic permeability is measured using a Cembureau constant head permeameter with nitrogen as the neutral percolating gas [16]. A general view of the device is given in Fig. 2.

The relative pressure $\left(P_{\mathrm{i}}-P_{\mathrm{atm}}\right)$ applied to the sample ranges between 0.05 and $0.3 \mathrm{MPa}$ and is read using a digital pressure gauge with an accuracy of $100 \mathrm{~Pa}$. Permeability measurements are carried out in an air-conditioned room $\left(20 \pm 1^{\circ} \mathrm{C}\right)$. Each disc is tested at five differential pressures: $0.05,0.1,0.15,0.2$, and $0.3 \mathrm{MPa}$. The establishing of the

Table 4

Drying procedure

\begin{tabular}{lcc}
\hline & OC & HPC and HFPC \\
\hline Drying stage $\mathrm{n}^{\circ} 1$ & 1 month at $60^{\circ} \mathrm{C}$ \\
Drying stage $\mathrm{n}^{\circ} 2$ & +1 month at $80^{\circ} \mathrm{C} \quad+1$ month at $105^{\circ} \mathrm{C}$ \\
Drying stage $\mathrm{n}^{\circ} 3$ & +2 months at $105^{\circ} \mathrm{C}$ \\
Drying stage $\mathrm{n}^{\circ} 4$ & +3 months at $105^{\circ} \mathrm{C}$ \\
\hline
\end{tabular}

steady state flow before actual measurements requires significant time (varying from $30 \mathrm{~min}$ to several hours). This condition is verified by taking two measurements separated by a 10 -min time interval. If two values differ by less than $2 \%$, the steady state flow condition is assumed to be achieved.

For each differential pressure, the apparent coefficient of permeability $k_{\mathrm{A}}\left(\mathrm{m}^{2}\right)$ is calculated from the Hagen-Poiseuille relationship, Eq. (1), for laminar flow of a compressible viscous fluid through a porous body [16].

$k_{\mathrm{A}}=\frac{Q}{A} \frac{2 \mu L P_{\mathrm{atm}}}{\left(P_{\mathrm{i}}^{2}-P_{\mathrm{atm}}^{2}\right)}$

$L$ : thickness of the sample (m); $A$ : cross-sectional area $\left(\mathrm{m}^{2}\right)$; $Q$ : measured gas flow $\left(\mathrm{m}^{3} / \mathrm{s}\right) ; \mu$ : coefficient of viscosity $\left(1.76 \times 10^{-5} \mathrm{~Pa} \mathrm{~s}\right.$ for nitrogen gas at $\left.20^{\circ} \mathrm{C}\right) ; P_{\mathrm{i}}$ : inlet pressure, i.e., applied absolute pressure $(\mathrm{Pa}) ; P_{\mathrm{atm}}$ : atmospheric pressure $(\mathrm{Pa})$.

In fact, the gas percolation through a fine porous body like concrete, especially HPC, can be regarded as resulting from two flow modes: viscous flow and slip flow or Knudsen flow. Various methods exist to calculate the nonviscous flow. The most widely used is the relationship proposed by Klinkenberg, Eq. (2), which introduces the notion of an intrinsic coefficient of permeability $k_{\mathrm{V}}\left(\mathrm{m}^{2}\right)$ relative to viscous flow only.

$k_{\mathrm{A}}=k_{\mathrm{V}}\left(1+\frac{b}{P_{\mathrm{m}}}\right)$

$P_{\mathrm{m}}$ : mean gas pressure, $P_{\mathrm{m}}=\left(P_{\mathrm{i}}+P_{\mathrm{atm}}\right) / 2 ; b$ : Klinkenberg coefficient $(\mathrm{Pa})$.

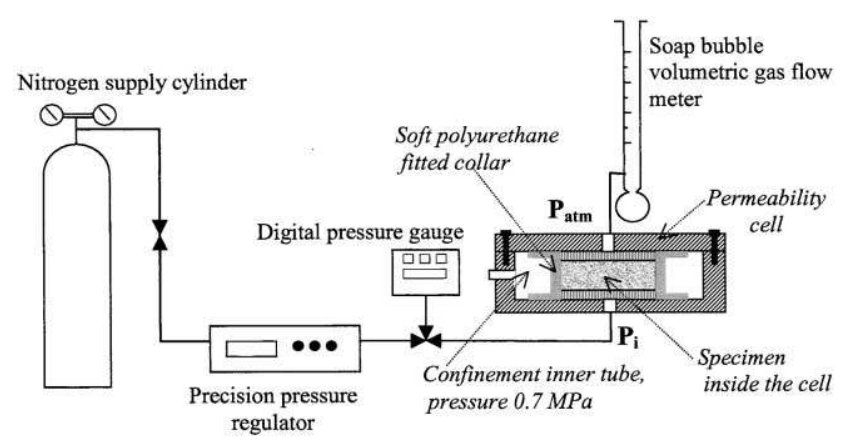

Fig. 2. Schematic layout of the experimental setup. 
$k_{\mathrm{V}}$ is the limiting value of gas permeability when the mean pressure $P_{\mathrm{m}}$ tends toward infinity. The determination of $k_{\mathrm{V}}$ consists in measuring $k_{\mathrm{A}}$ at different pressures $\left(\mathrm{P}_{\mathrm{i}}\right)$ and in plotting it against the inverse of the mean pressure $\left(1 / P_{\mathrm{m}}\right)$. From the five differential pressures applied, the correlations of the linear regressions are satisfactory with a coefficient higher than .99 .

The permeability is then regarded as the intrinsic gas permeability $k_{\mathrm{V}}$ determined in Eq. (2) and depending on the degree of water saturation of the tested concrete [13].

\section{Results and discussion}

\subsection{Degree of saturation after the drying stages}

After a drying period of 6 months in a ventilated oven at $105^{\circ} \mathrm{C}$, for HPCs and of 5 months for OC, the mass variation of discs does not exceed $0.07 \%$ for the HPCs, and $0.03 \%$ for the OC, over a 7-day time interval. At the end of the last drying stage, the mass of each sample is regarded as the dry reference. The samples, stored in water since the day after casting, are considered as the water saturated reference and give the water open porosity (Table 2). From these data, the degrees of saturation of the discs, after the first three drying stages, are presented in Fig. 3.

After the first drying stage, the degrees of saturation of the discs tend to decrease according to the applied load level. These changes in the kinetics of drying can be regarded as the first damage indicators. Damage modifies the porous structure of concrete because of microcracking, and then increases the hydrous diffusivity. This change is more noticeable for HPCs than for OC especially after the first drying stages.

For a given concrete mix, after drying stage 3 , and of course, after drying stage 4 , the water contents of each discs are very close, whatever the load level applied. Then, the changes in drying kinetics due to loading are assumed to have no influence on the degree of saturation of the discs of a series and, therefore, on their permeability measurement.

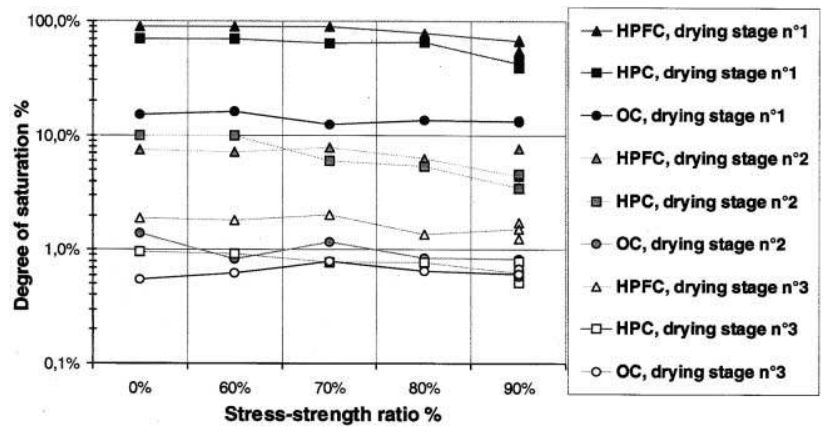

Fig. 3. Degree of water saturation of discs after the first three drying stages.

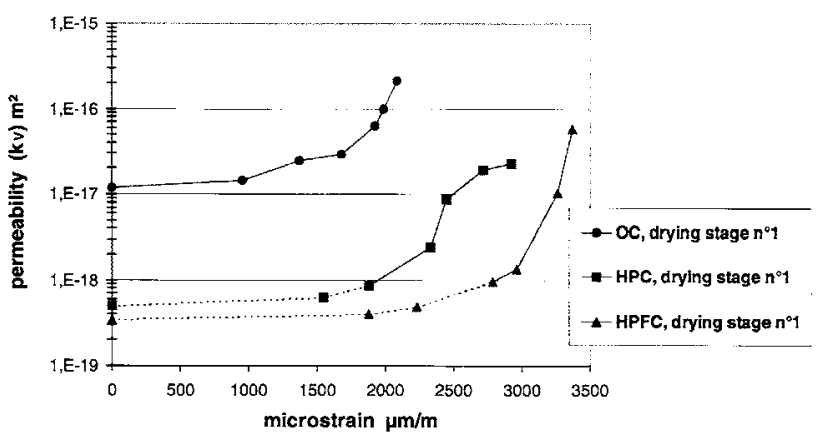

Fig. 4. Permeability versus maximum strain after drying stage 1.

\subsection{Strain-permeability relationship}

Among the various parameters recorded during testing, the maximum applied longitudinal strain is a first significant parameter, related to the increase in axial permeability of samples after unloading.

The residual strain could be another significant parameter. The strain recoveries observed decrease with the maximum applied strains and range from $95 \%$ to $82 \%$ for OC and from $97 \%$ to $86 \%$ for HPCs. But, the measured displacements are weak (about $30 \mu \mathrm{m}$ ) and the creep recovery (or delayed elasticity) of material is variable and still exist $30 \mathrm{~min}$ after unloading. Then, the precision of the residual strain measurement is low and this parameter is not regarded as a strain-permeability relationship in this study.

For each series, the maximum strain under loading is recorded for the three cylinders loaded at $90 \%$ of the mean maximum strength level, whatever the number of cycles. For this load level, a substantial difference in behavior is observed, the damage level from one concrete cylinder to another being variable. This observation may be explained by the heterogeneity of materials and the centering of the stresses in the cylinder.

The intrinsic permeability, $k_{\mathrm{v}}$, of discs extracted from the loaded concrete cylinders, after drying stages 1 and 4 are

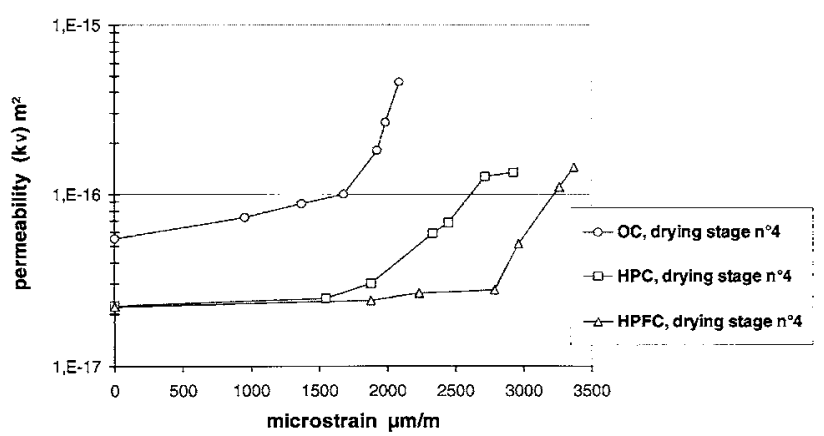

Fig. 5. Permeability versus maximum strain after drying stage 4 . 
shown in Figs. 4 and 5, respectively. It should be noted that after drying stage 1, the moisture content of HPC discs is higher than $70 \%$ (Fig. 3). Some water remains in the finest capillaries. Then, the gas permeability of the undamaged or little-damaged HPC discs can remain very low [15], e.g., lower than $8 \times 10^{-19} \mathrm{~m}^{2}$. The dotted lines (Fig. 4) are drawn up, using points whose permeability plotted in the graph is the apparent permeability $k_{\mathrm{A}}$ measured for only one inlet pressure $\left(P_{\mathrm{i}}=0.35 \mathrm{MPa}\right)$. The intrinsic permeability $k_{\mathrm{V}}$ is in reality still lower. After each drying stage, the three curves relating to each concrete type present the same evolution. The permeability of concrete varies according to the maximum strain applied.

The experiments show that if a similar strain is applied to both types of concrete, the permeability of HPCs is always lower than the permeability of OC. HPCs withstand larger strains. However, after moderate drying, their relative increase in gas permeability due to the applied strain is more important than OC (Fig. 4). HPFC withstand heavier stresses and consequently bigger strains, so steel-reinforced fibers would delay the crack formation in HPC when strain is growing.

\subsection{Increase in permeability versus applied-strain/yield- strain ratio}

To compare the increase in permeability of the different concrete versus the maximum applied strain during loading $(\varepsilon)$ is regarded according to the yield compressive strain $\left(\varepsilon_{\mathrm{y}}\right)$, which agrees within $3 \%$ (Table 2 ).

The interval of the relative increase in permeability of each concrete mix, after the last drying stage, is then narrower (Fig. 6). The absolute increases in permeability (Section 4.2) are especially checked for the most significant strains, i.e., from $80 \%$ of the yield compressive strain (Fig. 7). This threshold should correlate with the formation of a connected network of microcracks uniformly distributed throughout the matrix. After unloading, the microcracks narrow, although they do not close down completely $[4,5]$. This jump in permeability, close to the equivalent

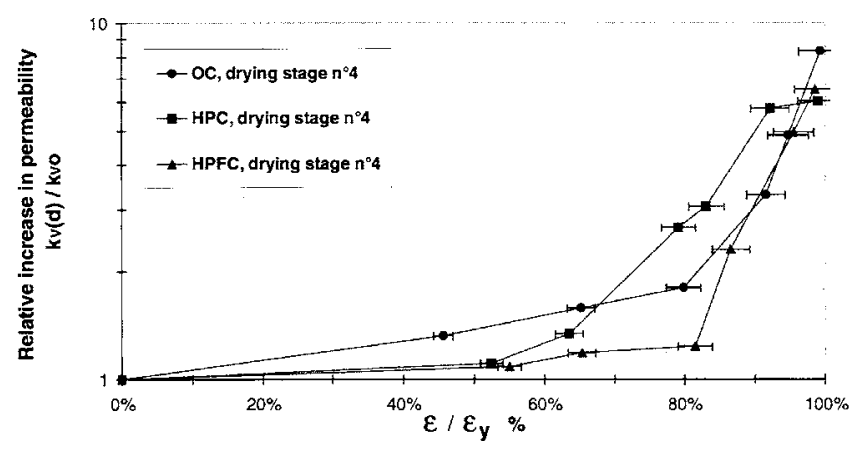

Fig. 6. Absolute increase in permeability (after the last drying stage) versus applied-strain/yield-strain ratio.

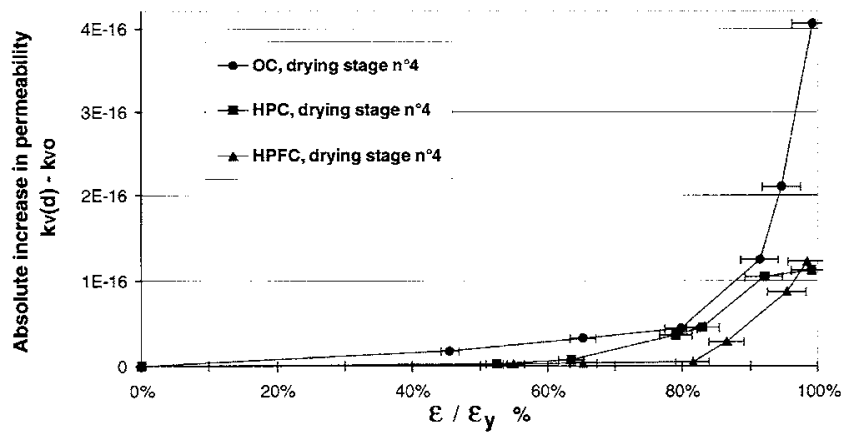

Fig. 7. Relative increase in permeability (after the last drying stage) versus applied-strain/yield-strain ratio.

stress-strain state, has been already observed during load testing $[8,9]$.

\section{Effect of drying}

\subsection{Partition of percolating gas flow}

The permeability of the four discs, coming from the central part of the sound cylindrical samples, is measured after each drying stage. The variations of these permeability values range between $20 \%$ and $10 \%$ and decrease with drying. The average of the four values is considered as the initial permeability $k_{\mathrm{V} 0}$ and is used as the reference value for the expression of permeability changes. $k_{\mathrm{V}(\mathrm{d})}$ is the permeability of the damaged concrete in the respective drying conditions.

The viscous gas flow through damaged samples can be divided into two flows, see Fig. 8:

- The gas flow percolating through an undamaged disc. It is the minimum flow proportional to $k_{\mathrm{V} 0}$;

- The difference between the total gas flow percolating through a damaged disc and the above flow. This difference is related to load-induced cracking and is proportional to the absolute increase in permeability (i.e., $k_{\mathrm{V}(\mathrm{d})}-k_{\mathrm{V} 0}$ ).

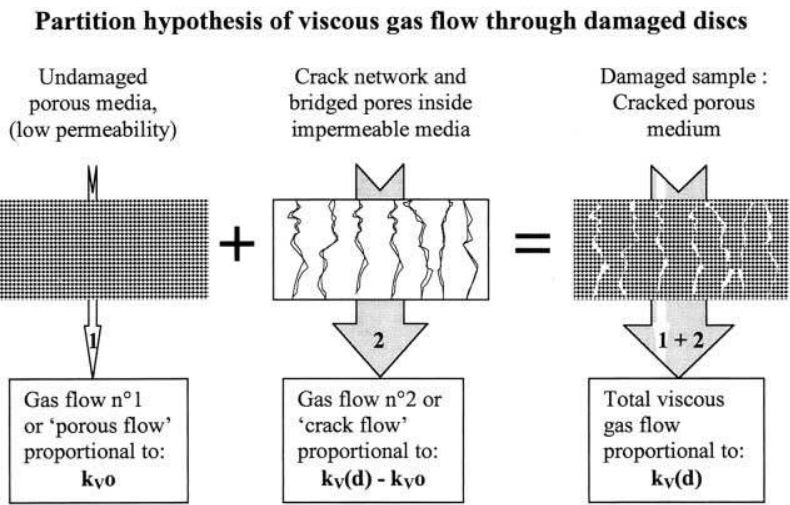

Fig. 8. Gas flow partition through damaged sample. 


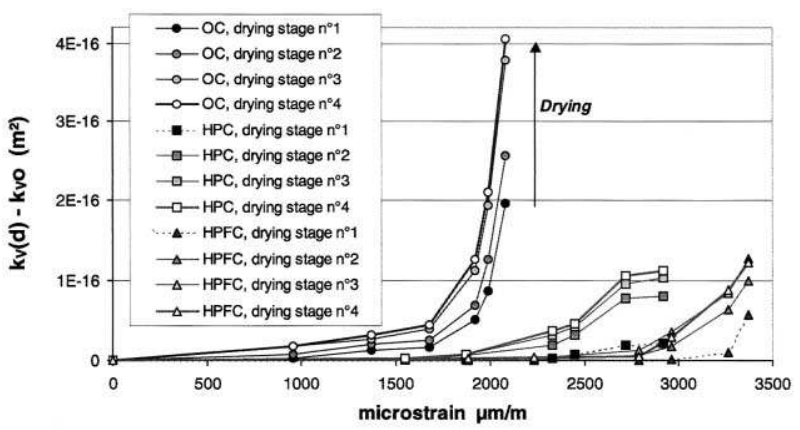

Fig. 9. Absolute increase in permeability after each drying stage.

Load-induced cracking is then regarded as a modification in the pore structure of concrete, including all cracks caused by the externally applied load, and all pores connected by these cracks.

\subsection{Absolute increase in permeability}

The effective difference, $k_{\mathrm{V}(\mathrm{d})}-k_{\mathrm{V} 0}$, rises with drying (Fig. 9). It is lower, however, than the difference plotted as dotted lines for HPCs after drying stage 1 (Section 3.2). During drying, due to capillary drift, the largest cracks or pores are first drained whereas some water remains in spaces of smaller diameter. With drying the diameter of emptied capillaries reduces. So the increase in the difference between $k_{\mathrm{V}(\mathrm{d})}$ and $k_{\mathrm{V} 0}$ with drying shows that strain-induced modifications take place on different scales of the pore structure. Damages produce a multiscale crack pattern inside the porous media. The increase in the absolute difference of permeability grows in a quasi-identical proportion in damaged samples at each applied strain step. We can then suppose that the crack size distribution in damaged samples of a given concrete type is roughly the same, whatever the applied strain.

Concerning the most damaged discs, even after the last stage of drying, the absolute increase in permeability is four times bigger in OC than in HPCs. The crack specific area, which conveys the gas flow, is then more important in OC than in HPCs.

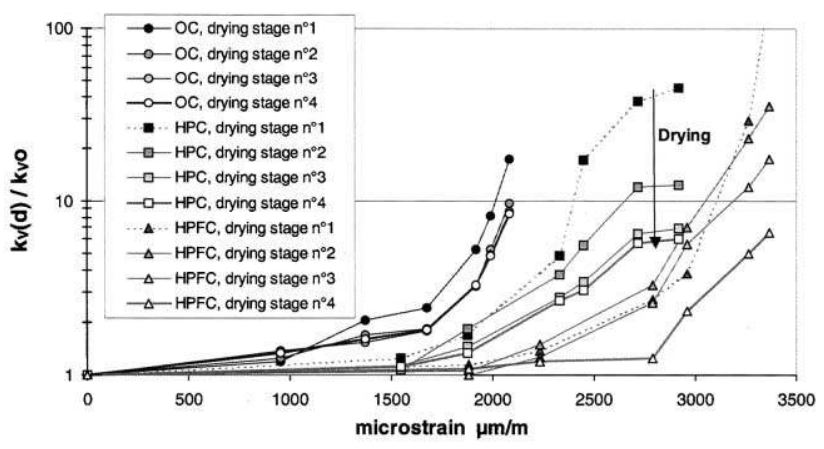

Fig. 11. Increase in permeability ratio after each drying stage.

\subsection{Relative increase in permeability}

The black arrows in Fig. 10 show that the relative increase in the permeability of OC and HPFC due to drying is more noticeable in undamaged or little damaged discs than in more damaged discs, especially for HPCs. The $k_{\mathrm{V}(\mathrm{d})} /$ $k_{\mathrm{V} 0}$ ratio then tends to decrease with drying (Fig. 11).

Two reasons account for this:

- Firstly, the damaged discs contain microcracks, which increase their hydrous diffusivity, and, therefore, their drying kinetics (Section 3.1). As the drying is partially completed, after 1 month at $60^{\circ} \mathrm{C}$, the degree of saturation thus decreases with the damage level while the gas permeability of discs increases $[13,14]$.

- Secondly, during the permeability testing of damaged samples, the crack pattern controls the global gas flow [1,2]. Cracks are first drained. A drying phase more important than in stage 1 makes it possible to drain smaller cracks or pores, which would only contribute to a limited flow to the total gas flow through the sample.

It should be noted that, after drying stage 1, effective ratios $k_{\mathrm{V}(\mathrm{d})} / k_{\mathrm{V} 0}$ are higher than ratios plotted as dotted lines for HPCs (Section 3.2). The sharp increase in gas permeability of HPCs is also due to their high degree of saturation after the moderate drying phase. Generally, results demonstrate that the degree of saturation amplify the effect of the applied strain on the gas permeability of concrete.

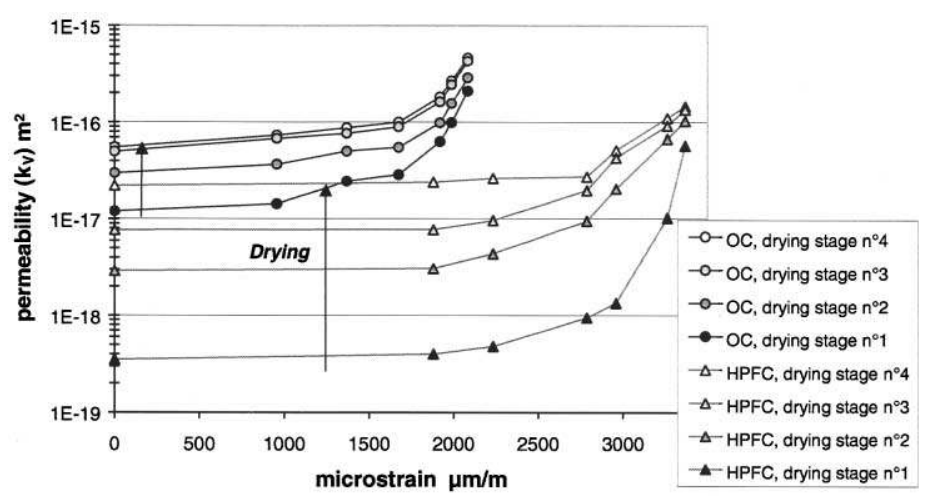

Fig. 10. Permeability of OC and HPFC versus maximum strain after each drying stage. 


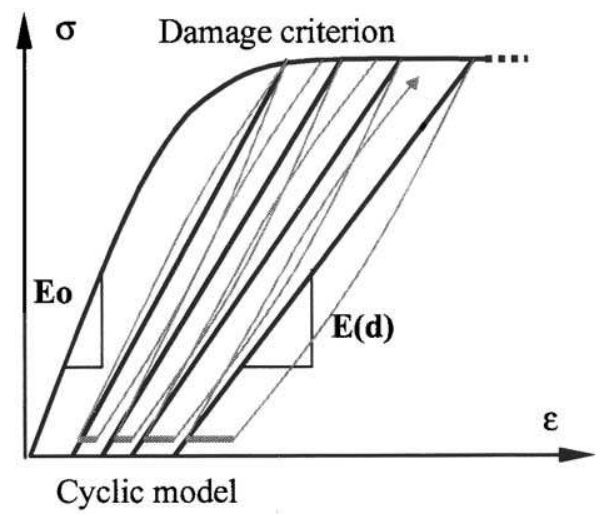

Fig. 12. Criterion of damage.

Between the last two drying stages, the relative increase in permeability is slight, and presupposes the stabilization of the permeability relating to the quasi-complete drainage of water inside the discs. To avoid any influence of the degree of saturation on the comparison of permeabilities, this increased ratio is considered for dried discs only (that is after drying stage 4).

\section{Damage-permeability relationship}

\subsection{Microstructural consideration}

To investigate crack characteristics, a video microscope with a magnification within the range $100 \times-200 \times$ and an oblique light is used to observe the cross section of the most damaged discs. Cracks of a 3- $\mu \mathrm{m}$ mean opening and a few millimeters long can then be detected [17]. A sample is also impregnated with colored dye, but reveals no crack pattern. Diffuse small cracks are only detected mainly near the coarse aggregates. The crack width and length are then smaller than $3 \mu \mathrm{m}$ and $5 \mathrm{~mm}$, respectively. Then, the increase in the total gas flow through damaged samples is due to diffuse damaging in the discs.

Cracking is assumed uniformly and randomly distributed within the volume of the cut discs. The material remains (on a macroscale) a homogeneous continuum whose characteristics are gradually and progressively changing. Nevertheless, despite its initial isotropy, the material becomes anisotropic [5,11]. This study demonstrates the existence of a link between the axial compressive damage caused by the uniaxial compressive load and the axial permeability.

However, in prepeak phase, the orientation of cracks are relatively isotropic at a microscopic level, partly due to the domination of interfacial cracks, which are randomly oriented [18]. So, in this first approach, the anisotropy of the damage is taken to be negligible. The completion of a database for nonlocal numerical prediction in prepeak phase requires regarding damage as the scalar value $d$, relative to an isotropic damage, the permeability, on the other hand, being still regarded as the axial permeability. Damage evaluation is then relative to the deterioration of the initial microstructure and the increase in permeability is its associated parameter.

\subsection{Criterion for damage evaluation}

Strain is the first criterion for damage evaluation of concrete. The correlation observed, Fig. 7, between applied-strain/yield-strain ratio and increase in permeability for each concrete type presupposes the existence of another correlation between damage and increase in permeability.

Damage evaluation can be deduced from the stressstrain curves recorded during loading. Several criteria exist to determine the decrease in the modulus of elasticity [11]. A criterion resulting from a plastic-fracturing model is necessary for the consideration of the plasticity of material, Fig. 12. The initial modulus of elasticity is $E_{0}$. The final modulus, $E_{(\mathrm{d})}$ is a fictive modulus of elasticity on full unloading way assumed as a straight line. The damage value $d$, is then regarded as the relative decrease in the modulus of elasticity: $d=\left(E_{0}-E_{(\mathrm{d})}\right) / E_{0}$ or $E_{(\mathrm{d})}=(1-d) E_{0}$.

Fig. 13, shows that the increase in permeability of all concrete types as a function of damaged value are similar. Concerning HPCs, the permeability grows significantly starting from a certain threshold of damage value, around 0.06 . Both evaluations show that the relative increases in permeability of HPCs are more sensitive to damage. This observation can be attributed to the brittle characteristic of HPCs.

\subsection{Ultrasonic damage evaluation}

The many tests carried on different rocks cylinders reveal a linear correlation between the dynamic modulus measured using this test method (Section 2.3) and the static modulus of elasticity [12]. Moreover, these linear correlations have been checked in case of anisotropy of the mechanical characteristics. The relative decrease in dynamic elastic longitudinal modulus is then regarded as the damage (i.e., $d=\left(E_{0 \mathrm{dyn}}-E_{(\mathrm{d}) \mathrm{dyn}}\right) / E_{0 \mathrm{dyn}}$ where $E_{0 \mathrm{dyn}}$ and $E_{(\mathrm{d}) \mathrm{dyn}}$ are the initial and final dynamic elastic modulus, respectively).

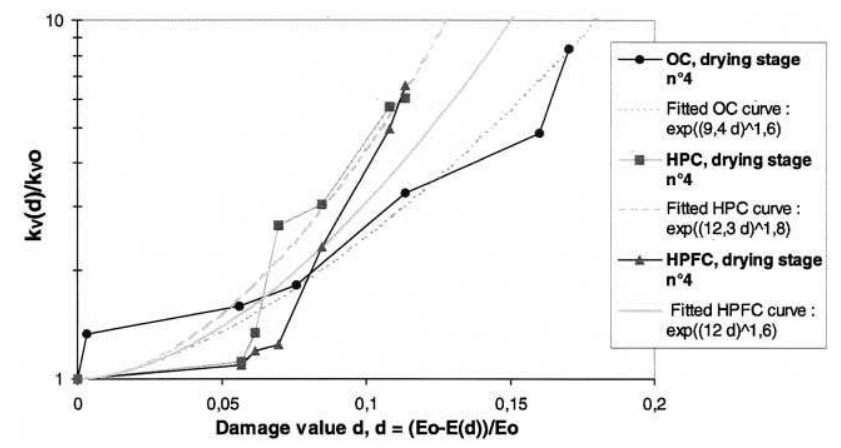

Fig. 13. Relation between increase in permeability and damage value from model criterion. 


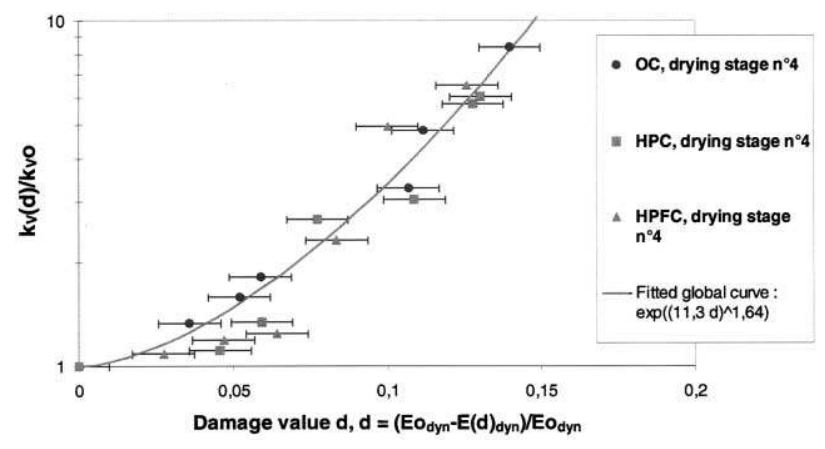

Fig. 14. Relation between increase in permeability and damage value from 'Grindosonic' evaluation.

The increases in the permeability ratio of each concrete type versus this damage evaluation are smaller in spite of the existence of an uncertainty about evaluations conducted with this experimental measurement (Fig. 14). An exponential regression is carried out by assuming the following relationship, Eq. (3):

$\frac{k_{\mathrm{V}(\mathrm{d})}}{k_{\mathrm{V} 0}}=\exp \left[(\alpha d)^{\beta}\right]$

$\alpha$ and $\beta$ are constant coefficients. This function is the result of an arbitrary choice to obtain an exponential form with a continuous increase and verifying the initial condition.

In Fig. 13, results are spread. The three fitted curves with each concrete type show that $\alpha$ ranges from 9.4 to 12.3 and $\beta$ from 1.6 to 1.8 , respectively.

In Fig. 14, the correlation coefficient of the regression of all experimental plots, common to the three concrete types, is .97, and $\alpha$ and $\beta$ are equal to 11.3 and 1.64, respectively, with $d$ ranging from 0 to .18 . This relationship, however, is an experimental evaluation to be confirmed for other concrete types with more experimental values. Nevertheless, it can be regarded as a first determination of the damaged-permeability relationship in the prepeak phase of concrete.

\section{Conclusions}

Compared to the undamaged sample, a uniaxial compressive load at $90 \%$ of the ultimate strength can increase the axial permeability by about one order of magnitude after unloading. This increase in permeability is valid for postloading specimens, knowing that during the loading phase it should be larger.

This increase in permeability is directly related to the maximum applied strain during loading and is due to the formation of a connected network of microcracks, which does not close down completely after the samples are unloaded. The effect of this nonreversible damage on permeability correlates, for each concrete type, with the applied-strain/yield-strain ratio.

The permeability of HPCs is always lower than the permeability of OC. The absolute increase in permeability of HPCs is lower, but after a moderate drying phase, their relative increase in permeability is bigger. In damaged specimens, the crack pattern controls the global gas flow with almost no influence on the degree of saturation.

If the damage value based on the decrease of the effective modulus of elasticity during the prepeak phase and the permeability increase ratio are considered, a damagedpermeability relationship valid for all concrete types studied could be worked out, in spite of the difficulty in achieving experimentally a precise determination.

\section{References}

[1] J.-M. Torrenti, O. Didry, J.-P. Ollivier, F. Plas, La dégradation des bétons, Hermès (Eds.), Paris, 1999.

[2] B. Gérard, D. Breysse, A. Ammouche, O. Houdusse, O. Dirdry, Cracking and permeability of concrete under tension, Mater. Struct. 29 (1996) $141-151$.

[3] K. Wang, D.C. Jansen, S.P. Shah, Permeability study of cracked concrete, Cem. Concr. Res. 27 (3) (1997) 381-393.

[4] H.R. Samaha, K.C. Hover, Influence of microcracking on the mass transport properties of concrete, ACI Mater. J. 89 (4) (1992) 416-424.

[5] N. Hearn, Effect of shrinkage and load-induced cracking on water permeability of concrete, ACI Mater. J. 96 (2) (1999) 234-241.

[6] A. Kermani, Permeability of stressed concrete, Build. Res. Inf. 19 (6) (1991) 361-365.

[7] C. Edvardsen, Water permeability and autogeneous healing of cracks in concrete, ACI Mater. J. 96 (4) (1999) 448-454.

[8] N. Hearn, G. Lok, Measurement of permeability under uniaxial compression - A test method, ACI Mater. J. 95 (6) (1998) 691-694.

[9] T. Sugiyama, T.W. Bremner, T.A. Holm, Effect of stress on gas permeability in concrete, ACI Mater. J. 93 (5) (1996) 443-450.

[10] A. Carpinteri, G. Ferro, I. Monetto, Scale effects in uniaxially compressed concrete specimens, Mag. Concr. Res. 51 (3) (1999) 217-225.

[11] J. Mazars, Thèse de doctorat d'état, LMT-Université Paris VI, 1984.

[12] B. Christaras, F. Auger, E. Mosse, Determination of the moduli of elasticity of rocks. Comparison of the ultrasonic velocity and mechanical resonance frequency methods with direct static methods, Mater. Struct. 27 (1994) 222-228.

[13] A. Abbas, M. Carcasses, J.-P. Ollivier, Gas permeability of concrete in relation to its degree of saturation, Mater. Struct. 32 (1999) 3-8.

[14] F. Jacobs, Permeability to gas of partially saturated concrete, Mag. Concr. Res. 50 (2) (1998) 115-121.

[15] D. Quenard, M. Carcasses, Gas permeability of concrete: Definition of a preconditioning procedure for measurements and crossover trials, 8th International Conference on Durability of Building Materials and Components, Vancouver, Canada (1) (1999) 236-245.

[16] J.J. Kollek, The determination of the permeability of concrete to oxygen by the Cembureau method - a recommendation, Mater. Struct. 22 (1989) 225-230.

[17] V. Picandet, A. Khelidj, G. Bastian, Effect of mechanical damaging on gas permeability of concrete, 2nd International Symposium on Cement and Concrete Technology, Istanbul, Turkey (2) (2000) 322-331.

[18] K.M. Nemati, P.J.M. Monteiro, K.L. Scrivener, Analysis of compressive stress-induced cracks in concrete, ACI Mater. J. 95 (5) (1998) $617-630$. 